\title{
Larval migration in PERL chambers as an in vitro model for percutaneous infection stimulates feeding in the canine hookworm Ancylostoma caninum
}

Daniela Franke ${ }^{1}$, Christina Strube ${ }^{1 *}$, Christian Epe ${ }^{2}$, Claudia Welz $^{1}$, Thomas Schnieder $^{1}$

\begin{abstract}
Background: Ancylostoma caninum third-stage larvae are the non-feeding infective stage of this parasite and are able to infect potential hosts via different infection routes. Since percutaneous infection is one of the most important routes and skin penetration is the first step into parasitic life, an existing in vitro model for percutaneous migration was modified and evaluated. The main parameter used to evaluate migration was the migration ratio (migrated larvae as a percentage of total number of larvae recovered). Additionally, the skin lag was calculated, expressing the percentage of larvae remaining in the skin and therefore not being recovered. Since initiation of feeding is proposed to be an important step in the transition from free-living to parasitic A. caninum larvae, feeding assays were performed with in vitro percutaneously migrated larvae. Additionally, infective larvae of $A$. caninum were activated via serum-stimulation and feeding behaviour was analysed and compared between percutaneously migrated and serum-stimulated larvae.
\end{abstract}

Results: Maximum skin migration levels of infective larvae were observed at temperatures above $32^{\circ} \mathrm{C}$ when larvae were placed on the epidermal side of skin for more than 12 hours. The medium beneath the skin had no effect on migration ratio, and no significant difference between the migration ratios through fresh and frozen/thawed skin was observed.

Maximum feeding levels of $93.2 \%$ were observed for percutaneously migrated larvae after $48 \mathrm{~h}$ incubation, whereas serum-stimulated larvae reached the maximum of $91.0 \%$ feeding larvae after $24 \mathrm{~h}$.

Conclusions: The PERL chamber system was optimised and standardised as an in vitro model for percutaneous migration. The larvae recovered after percutaneous migration showed characteristic signs of activation similar to that of serum-stimulated larvae. The observed difference in time course of resumption of feeding indicates that percutaneously migrated larvae are not identical to serum-stimulated larvae, which are currently representing the model for early parasitic stages.

\section{Background}

Hookworms are parasitic nematodes of major importance for humans and animals. Worldwide, an estimated 740 million people are infected with the human hookworms Necator americanus and Ancylostoma duodenale [1]. Furthermore, humans can suffer from the so-called Larva migrans cutanea, which is a percutaneously

\footnotetext{
* Correspondence: christina.strube@tiho-hannover.de 'Institute for Parasitology, University of Veterinary Medicine Hannover, Buenteweg 17, 30559 Hannover, Germany

Full list of author information is available at the end of the article
}

invading larva of other hookworm species, such as the canine hookworms Ancylostoma braziliense and Ancylostoma caninum [2]. Therefore, A. caninum is not only important as a model organism for human hookworms, but also as a zoonotic agent. The prevalence of $A$. caninum in canids is heavily dependent on the climatic region. Currently, there are not many detailed data on the prevalence of this parasite, as most researchers do not differentiate the hookworm species due to the morphological similarity of eggs representing the diagnostic stage. Traub et al. analysed the faeces of dogs in temple

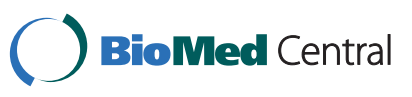

(c) 2011 Franke et al; licensee BioMed Central Ltd. This is an Open Access article distributed under the terms of the Creative Commons Attribution License (http://creativecommons.org/licenses/by/2.0), which permits unrestricted use, distribution, and reproduction in any medium, provided the original work is properly cited. 
communities in Bangkok by PCR and identified 9\% of dogs with $A$. caninum single infections and $14 \%$ with mixed infection of A. caninum and Ancylostoma ceylanicum [3]. In Ethiopia, a post-mortem analysis of stray dogs detected $70 \%$ to be infected with A. caninum [4]. In Europe, the prevalence is much lower: in a study conducted in Denmark, $0.6 \%$ of the examined foxes harboured A. caninum in their intestine [5]. A similar low prevalence was determined with $0.4 \%$ for Ancylostoma spp. by Dubna et al. for dogs in the Czech Republic [6].

The infective third-stage larvae (iL3) of A. caninum are sheathed and represent the non-feeding free-living stage of this parasite. These larvae are able to infect potential hosts via different infection routes of which the percutaneous infection seems to be of major importance [7]. The iL3 of A. caninum follow the "ambushing strategy", meaning that the larvae wait for their host to come across and then actively attach to the skin [8]. To find a possible host, A. caninum iL3 respond to host-like stimuli, such as warmth, $\mathrm{CO}_{2}$, and soluble skin extracts, with directed movement [9-11]. Once attached to an appropriate host, larvae exsheath and penetrate into the host's skin. First analyses support the involvement of several proteases, such as metallo- and aspartyl-proteases as well as hyaluronidases, in these processes [12-14]. As percutaneous migration represents the first parasitic activity of the individual hookworm larva, the aim of the present study was to particularly investigate this process and its influencing factors in more detail. Therefore an existing in vitro model for percutaneous migration [12] was modified and Franz glass diffusion chambers [15] were adapted to the experimental needs. The usefulness of the resulting PERL chamber (percutaneous larval migration chamber) for investigating the process of skin penetration was validated subsequently. Since resumption of feeding is proposed to be one of the first steps during development to parasitic larvae [16], in vitro percutaneously migrated larvae were analysed for food uptake and compared to the serum-stimulation method for iL3 described by Hawdon and Schad [16].

\section{Methods}

\section{Parasite and skin material}

Infective A. caninum larvae (iL3) were obtained from coprocultures of faeces from experimentally infected dogs and were collected using a modified Baermann technique. Afterwards larvae were stored in $\mathrm{H}_{2} \mathrm{O}$ without further purification at 5 to $7^{\circ} \mathrm{C}$ for up to 4 weeks. Prior to skin penetration assays larvae were incubated at room temperature for $1 \mathrm{~h}$ to mimic normal environmental conditions for percutaneous infection. The number of larvae per $\mathrm{ml}$ was determined by counting at least 3 aliquots of the suspension and calculating the mean. Animal infection experiments were conducted according the animal ethics guidelines of the Lower Saxony State Office for Consumer Protection and Food Safety (approved under licence no. AZ 509c-42502-01A38). Skin from freshly euthanized beagle dogs was obtained from the University's nearby Department of Pathology.

\section{PERL chamber assay}

For the in vitro migration assays PERL chambers (Figure 1) were designed. The design was based on Franz glass diffusion chambers [15] as archetype, consisting of a donor compartment, an acceptor compartment and a clamp to fix skin between both compartments. The acceptor compartment of each PERL chamber was filled with $2 \mathrm{ml}$ medium containing $50 \mu \mathrm{g} / \mathrm{ml}$ gentamicin, and skin was fixed between donor and acceptor compartment. Care was taken to ensure that there were no air bubbles beneath the skin. This was facilitated by the socalled sampling port of the PERL chamber. Following these preparations, the PERL chambers were preincubated for at least $30 \mathrm{~min}$ at the desired assay temperature in an incubator. Afterwards, 300 iL3 in 1X PBS (containing $50 \mu \mathrm{g} / \mathrm{ml}$ gentamicin) per chamber were added onto the skin. All migration assays were performed in darkness. After the incubation period, the liquid was collected from the donor compartment, and the compartment was washed with $0.5 \mathrm{ml} 1 \mathrm{X}$ PBS. Then the chamber was disassembled, and the acceptor medium was resuspended and also collected. The number of larvae that failed to penetrate skin (i.e. larvae remaining in the donor compartment), and the number of larvae that completely migrated through the skin (i.e. larvae that were collected from the acceptor compartment), were counted separately. The main parameter to assess migration was the migration ratio, expressing migrated larvae as percentage of the total number of recovered larvae of the respective chamber:

migration ratio (\%) $=\left[\right.$ larvae $_{\text {acceptor }} /\left(\right.$ larvae $_{\text {donor }}+$ larvae $\left.\left._{\text {acceptor }}\right)\right] \times 100$

To take into account that larvae may start migration but are not able to completely migrate through the skin, the skin lag was determined as a second parameter. The skin lag expresses the number of larvae from not being recovered from the respective chamber as percentage of the 300 larvae added onto the skin.

skin lag (\%) = [300 larvae $-\left(\right.$ larvae $_{\text {donor }}+$ larvae $\left._{\text {acceptor }}\right) /(300$ larvae $\left.)\right] \times 100$

The skin lag was used to compare parallel setups rather than setups from different experiments, as it is dependent on the actual number of larvae pipetted onto the skin, that may slightly differ between different lots of larval suspension.

Some samples of skin used during the migration assays were fixed in $10 \%$ Formalin (Roti ${ }^{\circledR}$ Histofix, 

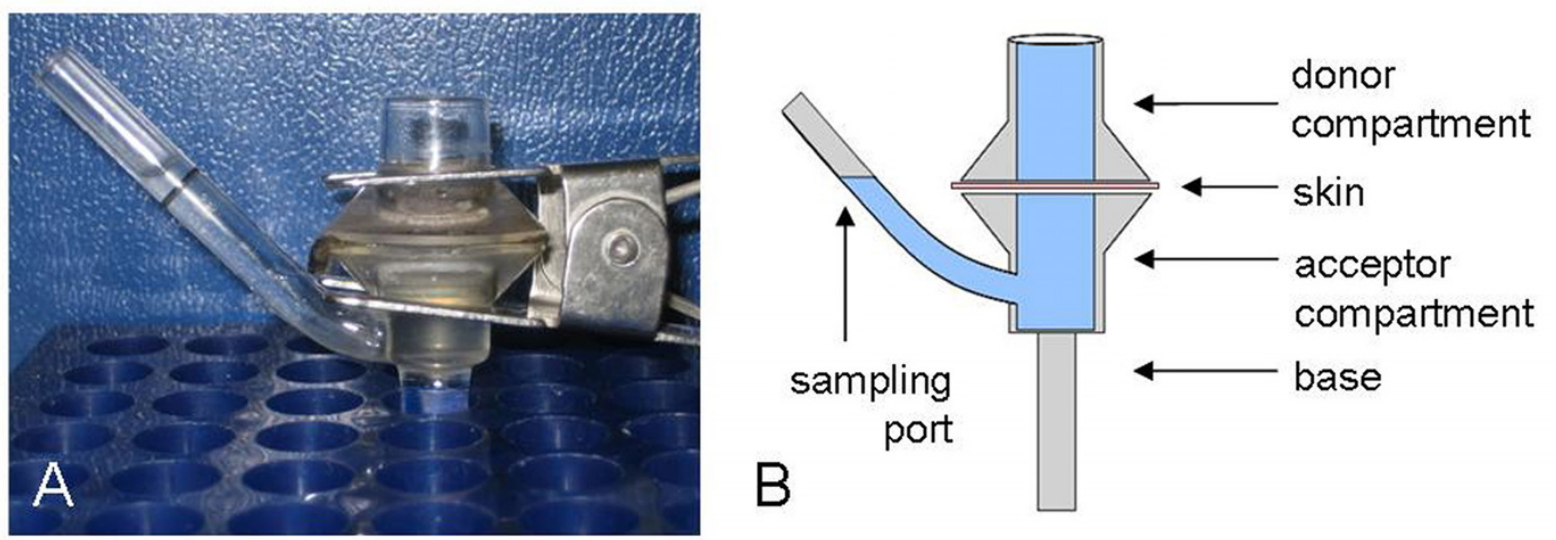

Figure 1 Illustration of an assembled PERL chamber system with a schematic drawing

ROTH) and finally cut and stained with HaematoxylinEosin (HE) to demonstrate migrating larvae.

\section{Evaluation of PERL chamber assay conditions}

To identify optimal conditions for percutaneous migration different influencing parameters were evaluated. In each migration experiment only one of these parameters was changed. If not subjected to evaluation, the standard parameters were as follows: $37^{\circ} \mathrm{C}$ migration temperature, no additional $\mathrm{CO}_{2}$, thawed skin placed with the epidermal side facing upwards, 1X PBS as acceptor medium and $12 \mathrm{~h}$ incubation time. All experiments were performed in triplicate and were repeated at least once. The following parameters were evaluated:

\section{Freshness of skin}

Skin of freshly euthanized beagle dogs was excised and shaved since pilot experiments showed that with unshaved skin the PERL chambers were leaky. Following shaving, subcutaneous adipose and loose connective tissue was largely removed. Care was taken to avoid any injury of the skin. Prior to the assays, the pieces of skin were examined macroscopically for damages, and only intact skin was used. Skin was used either immediately as fresh skin or stored at $-20^{\circ} \mathrm{C}$ prior to use. If frozen skin was used, skin was allowed to thaw for about $2 \mathrm{~h}$ at room temperature prior to preincubation.

\section{Temperature}

PERL chamber assays were performed at $7^{\circ} \mathrm{C}, 22^{\circ} \mathrm{C}, 32^{\circ} \mathrm{C}$ and $37^{\circ} \mathrm{C}$.

\section{Atmosphere}

Assays were performed with $5 \% \mathrm{CO}_{2}$ or without additional $\mathrm{CO}_{2}$.

\section{Migration time}

PERL chamber experiments were stopped after incubation times of $1 \mathrm{~h}, 4 \mathrm{~h}, 8 \mathrm{~h}, 12 \mathrm{~h}$ and $16 \mathrm{~h}$.

\section{Skin orientation}

Skin was presented to the added larvae in the acceptor compartment with the epidermal side upwards or downwards.

\section{Acceptor compartment medium}

The three tested media were 1X PBS, 1X PBS containing $10 \%$ dog serum, and $0.9 \% \mathrm{NaCl}$ solution. Serum was obtained from hookworm-naive dogs, filter-sterilized $(0.45 \mu \mathrm{m})$ and stored at $-20^{\circ} \mathrm{C}$. All media were supplemented with gentamicin $(50 \mu \mathrm{g} / \mathrm{ml}$ final concentration) to inhibit bacterial growth.

\section{Feeding assays}

Larvae migrated through skin in PERL chambers at $37^{\circ} \mathrm{C}$ with or without $5 \% \mathrm{CO}_{2}$ (percutaneously migrated larvae: $\mathrm{pmL} 3+\mathrm{CO}_{2}$ and $\mathrm{pmL} 3-\mathrm{CO}_{2}$ ), were incubated with $10 \%$ dog serum with or without $5 \% \mathrm{CO}_{2}$ (serum-stimulated larvae: ssL3 $+\mathrm{CO}_{2}$ and ssL3 $-\mathrm{CO}_{2}$ ) or were incubated without serum (negative control for serumstimulated larvae: ssL3nc $+\mathrm{CO}_{2}$ and ssL3nc $\left.-\mathrm{CO}_{2}\right)$. A detailed overview of the populations and their abbreviated names is given in Table 1.

\section{Skin penetration}

To produce percutaneously migrated larvae (pmL3 $-\mathrm{CO}_{2}$ ) for the feeding assays, the PERL chamber migration setups were performed with thawed skin with the epidermal side upwards and 1X PBS (containing $50 \mu \mathrm{g}$ / $\mathrm{ml}$ gentamicin) as acceptor medium at $37^{\circ} \mathrm{C}$ without additional $\mathrm{CO}_{2}$. The incubation time in the PERL chambers was 24 and $48 \mathrm{~h}$, respectively. Skin was removed in all assays after $24 \mathrm{~h}$, for $48 \mathrm{~h}$ incubation time larvae remained within the acceptor medium at $37^{\circ} \mathrm{C}$. In an alternative setup, the PERL chambers were incubated in the presence of $5 \% \mathrm{CO}_{2}$. After the incubation period, larvae were recovered from the acceptor compartments 
Table 1 Overview of analysed $A$. caninum larval populations

\begin{tabular}{|c|c|c|}
\hline Abbreviation & Population & Treatment \\
\hline iL3 & infective larvae & none; collected from coproculture \\
\hline $\mathrm{pmL} 3+\mathrm{CO}_{2}$ & $\begin{array}{l}\text { in presence of } \mathrm{CO}_{2} \text { percutaneously migrated } \\
\text { larvae }\end{array}$ & $\begin{array}{l}\text { migration within the PERL chamber system; incubation at } 37^{\circ} \mathrm{C} \text { in presence of } 5 \% \\
\mathrm{CO}_{2}\end{array}$ \\
\hline $\mathrm{pmL} 3-\mathrm{CO}_{2}$ & percutaneously migrated larvae & $\begin{array}{l}\text { migration within the PERL chamber system; incubation at } 37^{\circ} \mathrm{C} \text { without additional } \\
\mathrm{CO}_{2}\end{array}$ \\
\hline $\mathrm{ssL} 3+\mathrm{CO}_{2}$ & serum-stimulated larvae & incubation at $37^{\circ} \mathrm{C}$ in presence of $10 \%$ serum and $5 \% \mathrm{CO}_{2}$ \\
\hline $\begin{array}{l}\text { ssL3 }-\mathrm{CO}_{2} \\
\text { ssL3nc }+\mathrm{CO}_{2}\end{array}$ & $\begin{array}{l}\text { serum-stimulated larvae without } \mathrm{CO}_{2} \\
\text { negative control for serum-stimulated larvae }\end{array}$ & $\begin{array}{l}\text { incubation at } 37^{\circ} \mathrm{C} \text { in presence of } 10 \% \text { serum but without additional } \mathrm{CO}_{2} \\
\text { incubation at } 37^{\circ} \mathrm{C} \text { without serum but in presence of } 5 \% \mathrm{CO}_{2}\end{array}$ \\
\hline ssL3nc $-\mathrm{CO}_{2}$ & negative control & incubation at $37^{\circ} \mathrm{C}$ without serum and without additional $\mathrm{CO}_{2}$ \\
\hline
\end{tabular}

and incubated with fluorescein isothiocyanat-labelled bovine serum albumine (FITC-BSA, Sigma-Aldrich), following the method of Clokey and Jacobson [17] with some modifications. Briefly, larvae were transferred to plastic tubes and an equal volume of FITC-BSA solution ( $5 \mathrm{mg} / \mathrm{ml}$ in $1 \mathrm{X} \mathrm{PBS}$ ) was added to the suspension (final concentration $2.5 \mathrm{mg} / \mathrm{ml}$ ). Larvae were incubated for two hours using the initial incubation conditions and then washed three times in $2 \mathrm{ml} 1 \mathrm{X}$ PBS. At least 50 living larvae per PERL chamber were analysed for FITC-BSA uptake using a Zeiss fluorescence microscope (excitation 450-490 nm, barrier $520 \mathrm{~nm}$ ). The number of larvae that had ingested the labelled albumin was expressed as percentage of the total larvae counted. Furthermore, the percentage of exsheathed larvae was determined by counting at least 50 larvae per chamber. Each experiment was performed in duplicate or triplicate and was repeated at least once, resulting in six or more replicates.

\section{Serum-stimulation}

Approximately $300 \mathrm{~A}$. caninum iL3 were transferred into one well of a 24-well deep well plate. The wells were filled up to $750 \mu$ l either with $1 \mathrm{X}$ PBS containing $50 \mu \mathrm{g} / \mathrm{ml}$ gentamicin alone (negative control) or with $1 \mathrm{X}$ PBS containing $50 \mu \mathrm{g} / \mathrm{ml}$ gentamicin supplemented with filter sterilized $(0.45 \mu \mathrm{m})$ dog serum (final concentration $10 \%)$. Larvae were incubated at $37^{\circ} \mathrm{C}$ with $5 \% \mathrm{CO}_{2}$ and without additional $\mathrm{CO}_{2}$, respectively, for the desired incubation period ( $24 \mathrm{~h}$ or $48 \mathrm{~h}$ ). After incubation, an equal volume FITC-BSA solution ( $5 \mathrm{mg} / \mathrm{ml}$ in $1 \mathrm{X}$ PBS) was added to each well and the larvae were incubated for two more hours under the original incubation conditions, i.e. with or without $5 \% \mathrm{CO}_{2}$, respectively. The number of feeding and exsheathed larvae was determined as described above. Each experiment was set up in triplicate and was repeated at least once.

All statistical calculations were performed using the SigmaStat 3.1 software package (Systat Software, Inc.).
For comparison of two groups, a $t$-test was performed, followed by a Mann-Whitney Rank Sum Test in case data were not normally distributed. To compare more than two groups, One-Way ANOVA was performed and the Holm-Sidak method was used as post-hoc test. If the raw data were not normally distributed, a KruskalWallis One-Way Analysis of Variance on Ranks was done, followed by the Dunn's method. A p-value $<0.05$ was considered as statistically significant.

\section{Results}

\section{Skin penetration studies in PERL chambers}

Analysis of the impact of several experimental parameters on migration ratios resulted in the following data:

\section{Freshness of skin}

A. caninum larvae migrated through both, fresh and thawed canine skin (see Figure 2 for a histological

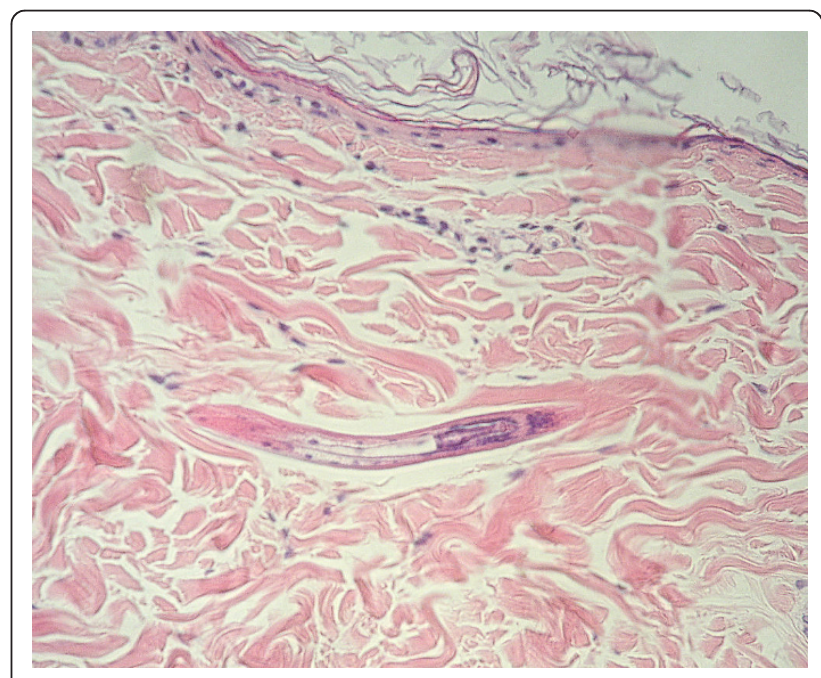

Figure 2 Larvae of $A$. caninum crossing dog skin in vitro Longitudinal section, HE-staining (400X magnification). 
section). The migration ratios of larvae did not differ significantly ( $\mathrm{t}$-test, $\mathrm{p}=0.893 ; \mathrm{t}=-0.138$ with 10 degrees of freedom) between experiments with fresh and thawed skin that had been stored at $-20^{\circ} \mathrm{C}$ previously. The mean migration ratios were $92.6 \%$ with a standard deviation (SD) of $5.1 \%$ for fresh skin and $93.0 \%(\mathrm{SD}=3.3 \%)$ for thawed skin. In contrast, there was a statistically significant difference ( $\mathrm{t}$-test, $\mathrm{p}=0.038 ; \mathrm{t}=2.395$ with 10 degrees of freedom) between the skin lags. These were $18.9 \%(\mathrm{SD}=5.3 \%)$ for fresh skin and $9.8 \%(\mathrm{SD}=7.7 \%)$ for thawed skin.

\section{Temperature}

The incubation temperature had significant effects on the migration ratios (Kruskal-Wallis One-Way ANOVA, $\mathrm{p}<0.001 ; \mathrm{H}=29.357$ with 3 degrees of freedom. For illustration of results refer to Figure 3 ). At $7^{\circ} \mathrm{C}$ no larvae were recovered from the acceptor compartment. With higher temperatures the migration ratio increased: at $22^{\circ}$ $\mathrm{C}$ incubation temperature, the mean migration ratio was $62.9 \%$, and at $32^{\circ} \mathrm{C}$ and $37^{\circ} \mathrm{C}$, respectively, the migration ratio was near $90 \%$ (detailed results including mean skin lag are listed in Table 2). The migration ratios at $32^{\circ} \mathrm{C}$ and $37^{\circ} \mathrm{C}$ were not statistically significantly different (Dunn's test, $\mathrm{p}>0.05$ ), in contrast to the differences to the migration ratios at lower temperatures (Dunn's test, $\mathrm{p}<0.05)$. The skin lag was also significantly different between the setups (One-Way ANOVA; $\mathrm{p}<0.001$ ). It

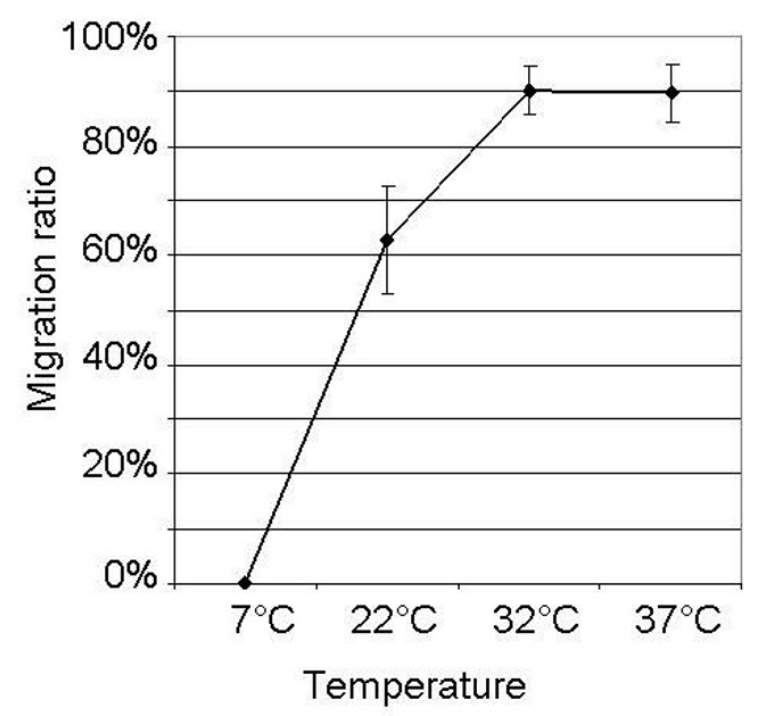

Figure 3 Effect of temperature on the migration ratio of L3 after $\geq 12 \mathrm{~h}$ of incubation. Each point represents the mean \pm SD $(\mathrm{n}=6)$. Larvae were incubated in PERL chambers at $7^{\circ} \mathrm{C}, 22^{\circ} \mathrm{C}, 32^{\circ} \mathrm{C}$, and $37^{\circ} \mathrm{C}$, respectively. was highest at an incubation temperature of $22^{\circ} \mathrm{C}$ and significantly higher than the skin lag at $32^{\circ} \mathrm{C}$ and $37^{\circ} \mathrm{C}$, respectively. Furthermore, the skin lag at $7^{\circ} \mathrm{C}$ was significantly higher than at $32^{\circ} \mathrm{C}$ (Holm-Sidak method, p < 0.01 ). The skin lag did not differ significantly between the experiments at $32^{\circ} \mathrm{C}$ and $37^{\circ} \mathrm{C}$, neither did the skin lag at $7^{\circ} \mathrm{C}$ from those at $22^{\circ} \mathrm{C}$ and $37^{\circ} \mathrm{C}$ (Holm-Sidak method, $\mathrm{p}>0.01$ ).

\section{Atmosphere}

The migration ratio of larvae in presence of $5 \% \mathrm{CO}_{2}$ was significantly lower $(78.4 \%$; $\mathrm{SD}=13.4 \%$; t-test, $\mathrm{p}=0.023$; $\mathrm{t}=2.673$ with 10 degrees of freedom) than the migration ratio of larvae without additional $\mathrm{CO}_{2}$ (94.5\%; $\mathrm{SD}=$ 6.0\%). The skin lag was not significantly different ( $t$-test, $\mathrm{p}=0.159 ; \mathrm{t}=1.523$ with 10 degrees of freedom).

\section{Incubation time}

The incubation time (Figure 4) during that larvae were allowed to migrate had a significant effect on the migration ratio (Kruskal-Wallis One-Way ANOVA, $\mathrm{p}<0.001$; $\mathrm{H}=30.241$ with 5 degrees of freedom) and skin lag (OneWay ANOVA, $\mathrm{p}<0.001)$. After 1 hour of incubation most of the applied 300 larvae had invaded the skin, as the mean number of larvae recovered from the donor compartment was $42.33(\mathrm{SD}=10.98)$, but the larvae could not be recovered from the acceptor compartment at that time point (Figure 4A). Therefore, the migration ratio was $0 \%$ for $1 \mathrm{~h}$ incubation time and increased over time (Figure $4 \mathrm{~B})$. The mean migration ratios were highest for incubation periods of $12 \mathrm{~h}$ and more (detailed results including mean skin lag are listed in Table 3). These migration ratios were not significantly different from each other (Dunn's test, $\mathrm{p}>0.05$ ) but from that after $1 \mathrm{~h}$ incubation (Dunn's test, $\mathrm{p}<0.05)$. The mean skin lag also decreased from shorter to longer incubation periods. The skin lag was not statistically significant between the experiments with $1 \mathrm{~h}$ and $4 \mathrm{~h}$ incubation time and between the experiments with incubation periods of $12 \mathrm{~h}$ and longer (Holm-Sidak method, $p>0.01$ ). All other comparisons detected significant differences (Holm-Sidak method, $\mathrm{p}<0.01$ ).

\section{Orientation of skin}

Migrating larvae preferred to migrate through skin from the epidermal to the dermal side. With the epidermal side upwards the mean migration ratio was $90.3 \%$ ( $\mathrm{SD}=$ $4.1 \%$ ) compared to $81.0 \%(\mathrm{SD}=1.7 \%)$, when larvae had to invade the dermal side instead of the epidermal side ( $\mathrm{t}$-test, $\mathrm{p}<0.001 ; \mathrm{t}=5.246$ with 10 degrees of freedom). The skin lag for experiments with the epidermis upwards was $15.4 \%$ ( $\mathrm{SD}=9.7 \%$ ), and the lag for experiments with the dermis upwards was $28.5 \%(\mathrm{SD}=11.3 \%)$. This difference was not statistically significant (t-test, $\mathrm{p}=0.057$; $\mathrm{t}=$ -2.155 with 10 degrees of freedom).

\section{Acceptor medium}

The medium within the acceptor compartment did not have a significant effect on the migration ratio of larvae 
Table 2 Influence of temperature on migration ratio and skin lag $(n=6)$

\begin{tabular}{lll}
\hline Temperature & $\begin{array}{l}\text { Mean migration ratio }( \pm \\
\text { standard deviation }(\mathrm{SD}))\end{array}$ & $\begin{array}{l}\text { Mean skin lag }( \pm \\
\text { standard deviation } \\
(\mathrm{SD}))\end{array}$ \\
\hline $7^{\circ} \mathrm{C}$ & $0.0 \%{ }^{*}( \pm .0 \%)$ & $30.0 \%( \pm 18.1 \%)$ \\
$22^{\circ} \mathrm{C}$ & $62.9 \%^{*}( \pm 9.9 \%)$ & $39.7 \%{ }^{* *}( \pm 13.4 \%)$ \\
$32^{\circ} \mathrm{C}$ & $90.2 \%( \pm 4.4 \%)$ & $11.8 \%( \pm 10.8 \%)$ \\
$37^{\circ} \mathrm{C}$ & $89.7 \%( \pm 5.3 \%)$ & $12.0 \%( \pm 9.2 \%)$ \\
\hline
\end{tabular}

* Statistically significant difference to migration ratio at $37^{\circ} \mathrm{C}, \mathrm{p}<0.05$ (Dunn's test). ** Statistically significant difference to skin lag at $37^{\circ} \mathrm{C}, \mathrm{p}<0.001$ (Holm-Sidak test).

(One-Way-ANOVA, $\mathrm{p}=0.952$ ). The mean migration ratios were $89.5 \%$ for $1 \mathrm{X}$ PBS (SD = 5.6\%), $89.7 \%$ for $1 \mathrm{X}$ PBS supplemented with $10 \%$ dog serum $(\mathrm{SD}=4.7 \%)$, and $90.3 \%$ for $0.9 \% \mathrm{NaCl}$ solution $(\mathrm{SD}=4.1 \%)$. The skin lag was $17.2 \%(\mathrm{SD}=9.3 \%)$ for $1 \mathrm{X} \mathrm{PBS}, 13.2 \%(\mathrm{SD}=7.3 \%)$ for 1X PBS enriched with dog serum, and 17.6\% (SD = 9.4\%) for $0.9 \% \mathrm{NaCl}$ solution. There was no statistically significant difference between these results (One-WayANOVA, $\mathrm{p}=0.639$ ).

\section{Experiments under standard conditions}

The mean migration ratio of all experiments under standard conditions $(\mathrm{n}=48$; thawed skin, epidermal side up, $37^{\circ} \mathrm{C}$ incubation temperature, no additional $\mathrm{CO}_{2}, \geq 12 \mathrm{~h}$ incubation time, 1X PBS as acceptor medium) was $91.1 \%$, $\mathrm{SD}=4.6 \%$. The mean skin lag was $15.5 \%, \mathrm{SD}=11.9 \%$.

\section{Feeding assays}

All tested larval populations, i.e. pmL3 $-\mathrm{CO}_{2}$, ssL3 $+\mathrm{CO}_{2}$, ssL3 $-\mathrm{CO}_{2}$, ssL3nc $+\mathrm{CO}_{2}$, and ssL3nc $-\mathrm{CO}_{2}$ (for an overview refer to Table 1), were vital and mobile after incubation except for larvae that had migrated through skin in presence of $5 \% \mathrm{CO}_{2}\left(\mathrm{pmL} 3+\mathrm{CO}_{2}\right)$. Although many larvae succeeded to migrate through the skin as described above, the majority of pmL3 $+\mathrm{CO}_{2}$ was dead after $48 \mathrm{~h}(91.1 \%, \mathrm{SD}=6.6 \%)$.

\section{Feeding}

Larvae that had started pharyngeal pumping exhibited gut fluorescence as a consequence of ingested FITCBSA (Figure 5). The differences between the populations were statistically significant (Kruskal-Wallis One-Way ANOVA, $\mathrm{p}<0.001 ; \mathrm{H}=64.408$ with 5 degrees of freedom). The population with the highest percentage of feeding after $24 \mathrm{~h}$ were the ssL3 $+\mathrm{CO}_{2}$ (usually called serum-stimulated larvae). Statistically, the ratio of feeding larvae was similar after $48 \mathrm{~h}$. The feeding level of the percutaneously migrated larvae pmL3 $-\mathrm{CO}_{2}$ at both time points was statistically not significantly different from that of the ssL3 +CO, (Dunn's test, $\mathrm{p}>0.05$ ), nonetheless, the increase over time was statistically

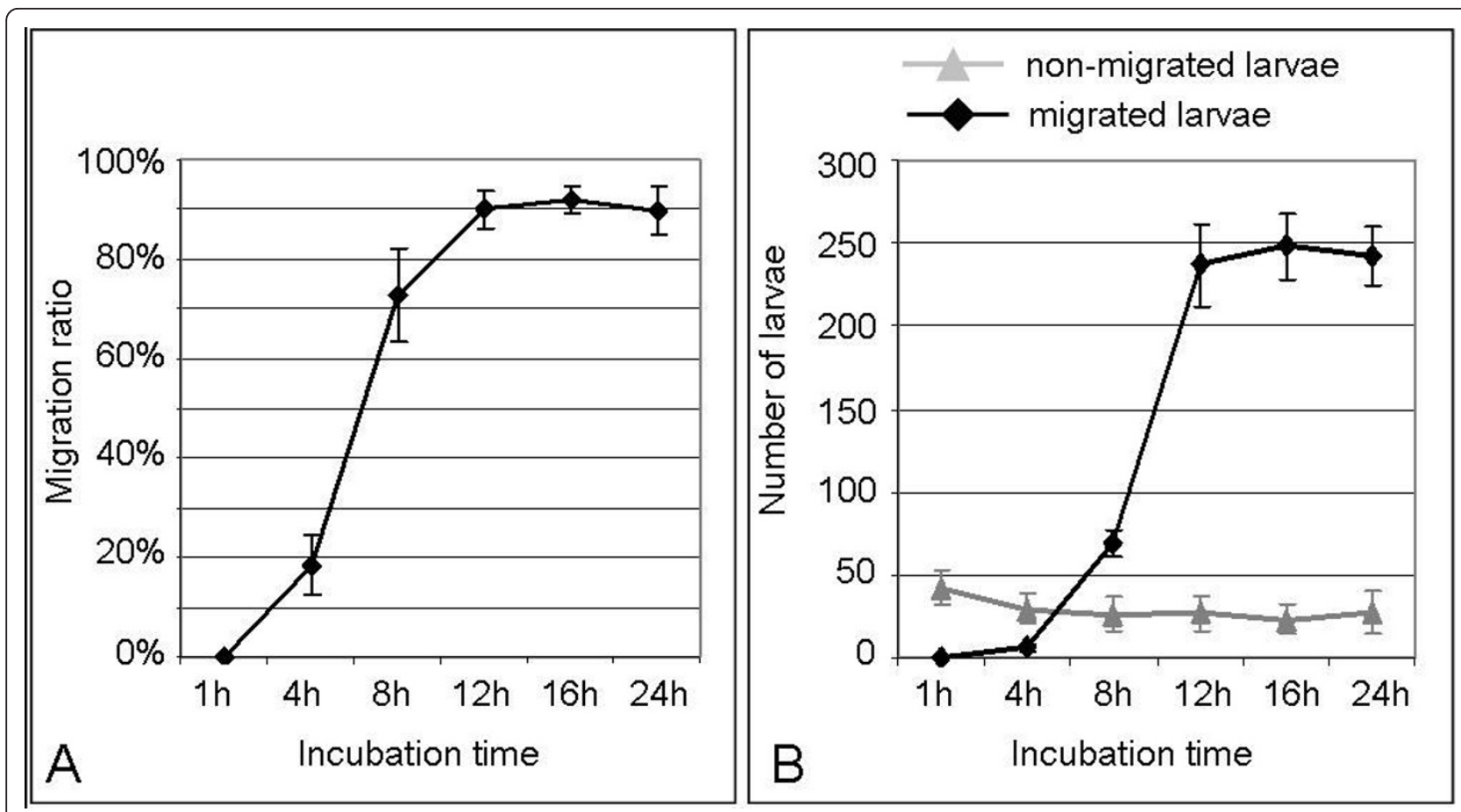

Figure 4 Effect of incubation period on the migration behaviour of the L3. Each point represents the mean \pm SD $(n=6)$. Larvae were incubated in PERL chambers for $1 \mathrm{~h}, 4 \mathrm{~h}, 8 \mathrm{~h}, 12 \mathrm{~h}, 16 \mathrm{~h}$, and $24 \mathrm{~h}$, respectively. A: Migration ratio over time. B: Total number of larvae recovered from the donor compartment (non-migrated larvae) and from the acceptor compartment (migrated larvae). 
Table 3 Influence of incubation period on migration ratio and skin lag $(n=6)$

\begin{tabular}{lll}
\hline $\begin{array}{l}\text { Incubation } \\
\text { time }\end{array}$ & $\begin{array}{l}\text { Mean migration ratio }( \pm \\
\text { standard deviation (SD) }\end{array}$ & $\begin{array}{l}\text { Mean skin lag }( \pm \\
\text { standard deviation } \\
(S D))\end{array}$ \\
\hline $1 \mathrm{~h}$ & $0.0 \% *( \pm 0.0 \%)$ & $85.9 \%^{* *}( \pm 3.7 \%)$ \\
$4 \mathrm{~h}$ & $18.3 \%( \pm 6.0 \%)$ & $88.0 \% * * \pm 3.5 \%)$ \\
& & \\
$8 \mathrm{~h}$ & $72.8 \%( \pm 9.3 \%)$ & $68.4 \% * * \pm 3.5 \%)$ \\
$12 \mathrm{~h}$ & $90.0 \%( \pm 3.8 \%)$ & $12.2 \%( \pm 8.9 \%)$ \\
$16 \mathrm{~h}$ & $92.0 \%( \pm 2.7 \%)$ & $9.8 \%( \pm 9.0 \%)$ \\
$24 \mathrm{~h}$ & $90.0 \%( \pm 4.9 \%)$ & $10.0 \%( \pm 3.8 \%)$ \\
\hline
\end{tabular}

* Statistically significant difference from migration ratio after $\geq 12 h, p<0.05$ (Dunn's test). ${ }^{*}$ Statistically significant difference from skin lag after $\geq 12 \mathrm{~h}, \mathrm{p}$ $<0.001$ (Holm-Sidak test).

significant (Mann-Whitney Rank Sum Test, $\mathrm{p}=0.001$; T $=115.0$ ). Detailed results are illustrated in Figure 6.

\section{Exsheathment}

Migrated larvae (pmL3 $-\mathrm{CO}_{2}$ as well as pmL3 $+\mathrm{CO}_{2}$ ) were completely exsheathed, and the larvae incubated with serum (ssL3 $+\mathrm{CO}_{2}$ and ssL3 $-\mathrm{CO}_{2}$ ) were almost completely exsheathed. The control populations (ssL3nc $+\mathrm{CO}_{2}$ and ssL3nc $-\mathrm{CO}_{2}$ ) showed significantly lower percentages of exsheathment (Kruskal-Wallis One-Way ANOVA, p < $0.001 ; \mathrm{H}=69.435$ with 5 degrees of freedom). The exsheathment ratios of these populations were not significantly different from each other (Dunn's test, $\mathrm{p}>0.05$ ). Results are shown in more detail in Figure 7. A Two-Way ANOVA with the stimulus (migration, serum, or none of

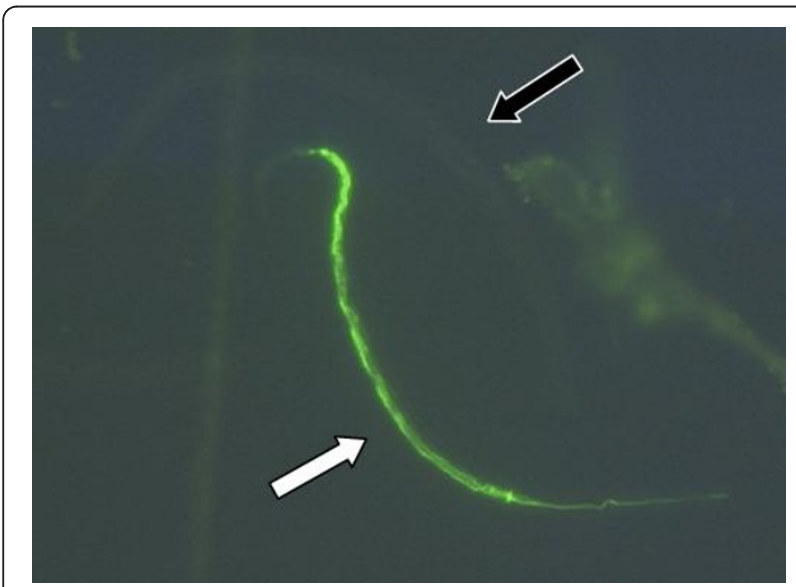

Figure 5 Feeding of $A$. caninum L3 on FITC-BSA after in vitro percutaneous migration. Larvae were collected after percutaneous migration from the acceptor compartment of a PERL chamber and incubated with FITC-BSA as described for the serum-stimulation protocol. No serum was added. In contrast to the non-feeding larva above (black arrow), the positive larva (white arrow) exhibits a strong fluorescence from the gut them) as first factor and the atmosphere (additional $\mathrm{CO}_{2}$ present or absent) revealed that $\mathrm{CO}_{2}$ had no obvious impact on exsheathment $(\mathrm{p}=0.487$ after $24 \mathrm{~h}$ and $\mathrm{p}=$ 0.124 after $48 \mathrm{~h}$ ). In contrast, the stimulus had a significant impact ( $\mathrm{p}<0.001$ after $24 \mathrm{~h}$ and $48 \mathrm{~h}$ ). Exsheathment was significantly higher upon either the serum or the migration stimulus than without an additional stimulus (HolmSidak method, $\mathrm{p}>0.001)$. There was no significant difference between the exsheathment in migrated and serumstimulated larvae (Holm-Sidak method, $\mathrm{p}>0.001)$. No interaction was detected between the two factors $(\mathrm{p}=$ 0.553 after $24 \mathrm{~h}, 0.106$ after $48 \mathrm{~h}$ ).

\section{Discussion}

\section{Skin penetration studies}

The ability of infective hookworm larvae to enter their host has been intriguing to researchers for many years. Early experiments were performed by Goodey in 1922 [18]. Since then, migration behaviour of hookworm larvae has been subject of several studies to analyse the mechanism of skin penetration [12], to evaluate the impact of protease inhibitors and antisera [13,19-21], or as a parameter of fitness [22].

The present study aimed to establish an in vitro migration model as a reliable system to achieve reproducible and comparable results. Migrated larvae are often calculated as percentage of the original number of larvae, i.e. the number of larvae that had been calculated to be pipetteted. Practically, pipetting of exactly 300 larvae is not possible. To take these variations into account, in the present study the migration ratio was defined as migrated larvae as percentage of the number of larvae recovered from both compartments. This calculation excludes the possibility of migration ratios lower than $0 \%$ and higher than $100 \%$ and minimizes the effect of slightly variable absolute numbers of larvae. This is especially important to allow comparison of migration ratios from experiments using different lots of larvae suspensions. As this calculation omits larvae that started migration but did not succeed to completely migrate through the skin, the "skin lag" was introduced as additional parameter. It expresses the difference between the sum of larvae recovered from both compartments and the theoretically used total number of 300 larvae as percentage of 300 larvae. A higher skin lag compared to the respective control assay under standard conditions within the same experiment indicates that larvae for example remained in the skin and therefore could not be counted. The skin lag should be used to compare the results of parallel setups rather than from experiments using different lots of larvae suspensions.

Furthermore, the models as well as the experimental conditions vary between the different research groups 


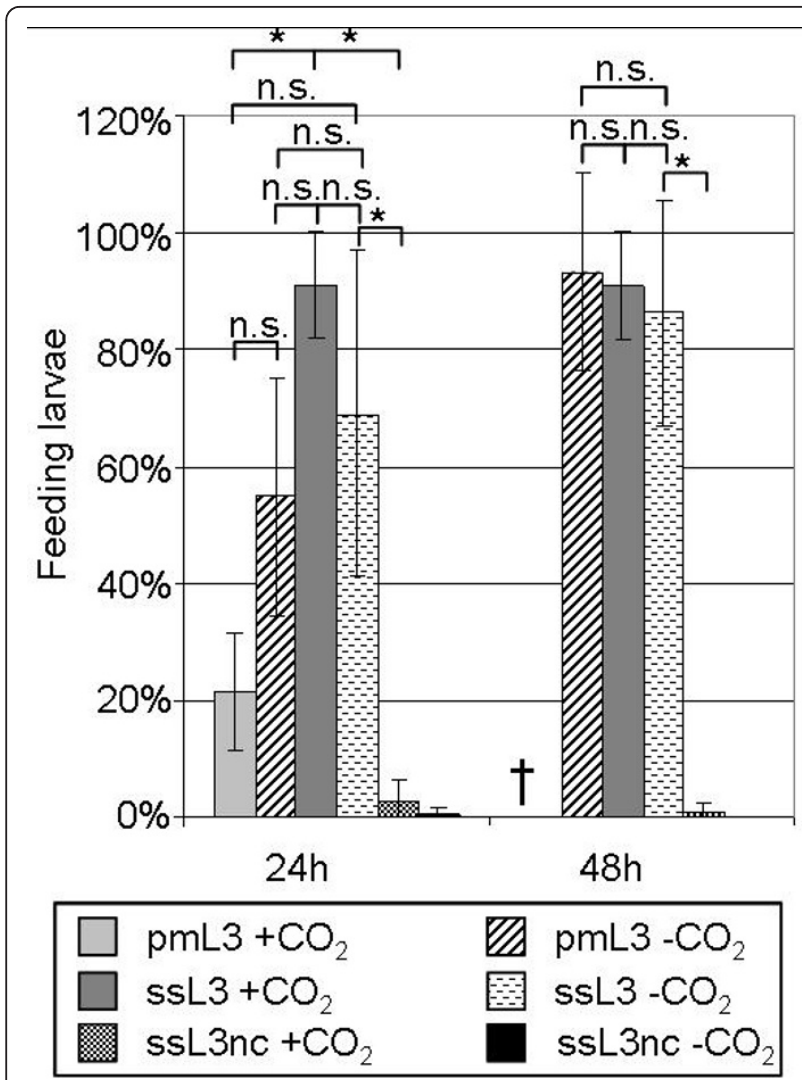

Figure 6 Mean feeding ratio of the different larval populations \pm SD $(n \geq 6)$. Larvae were incubated either in PERL chambers or with or without serum, and with or without $\mathrm{CO}_{2}$ (for detailed overview of populations refer to Table 1). The percentage of feeding larvae was determined after $24 \mathrm{~h}$ and $48 \mathrm{~h}$, respectively, using FITC-BSA as described for the serum-stimulation protocol. For each setup, at least 50 live larvae were examined for uptake of FITCBSA. *: statistically significant difference ( $p \leq 0.05)$; n.s.: not significant; t: no data since most of the larvae died.

which may lead to non-comparable results as these parameters might influence the migration. Therefore, the possible impact of different factors on the results of in vitro migration experiments was evaluated.

The use of thawed skin instead of fresh skin has the advantage of a higher practicability and flexibility. Furthermore, freezing allows using skin of one individual more efficiently, for example if there is a limit in the number of available PERL chambers, space in the incubator or simply time. The use of frozen skin also allows to obtain skin opportunistically from clinics or pathology, and to store it, so that for animal welfare reasons no purpose-collected skin from animals was needed. Consequently, comparison experiments started with this parameter. From pharmacological trials analysing transdermal absorption, different results regarding the comparability of fresh and thawed skin are known. According to Franz [15] and Harrison et al. [23],

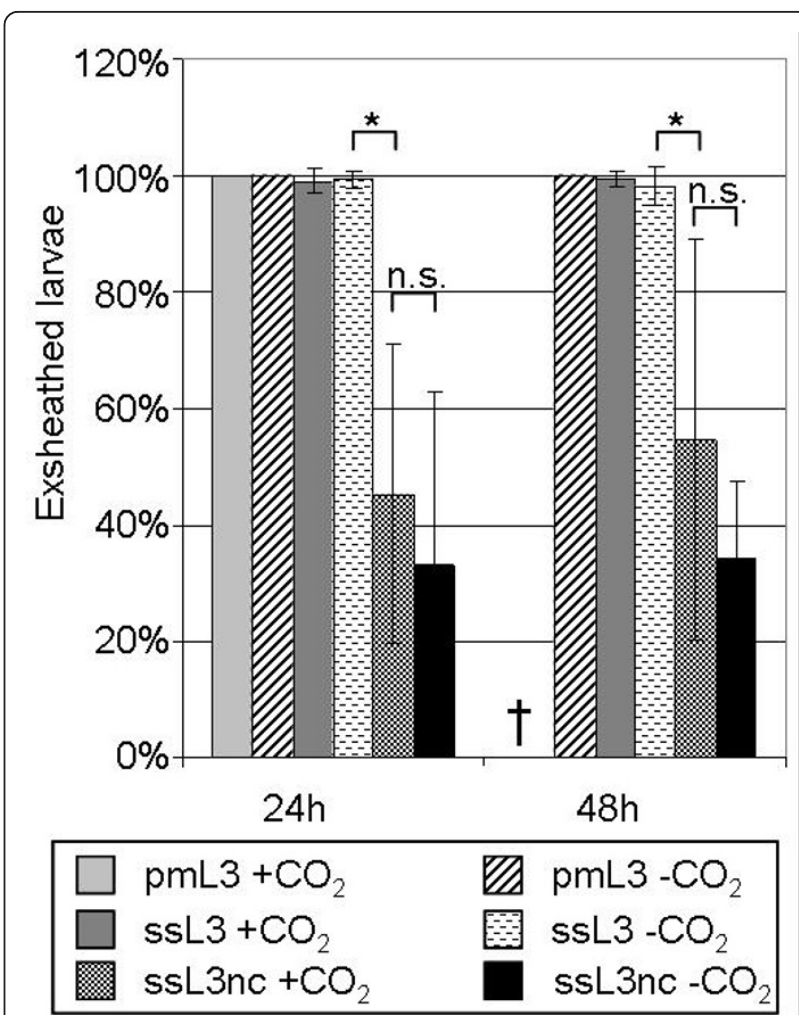

Figure 7 Mean exsheathment ratio of the different larval populations $\pm S D(n \geq 6)$. Larvae were incubated either in PERL chambers or with or without serum, and with or without $\mathrm{CO}_{2}$ (for detailed overview of populations refer to Table 1). The percentage of exsheathed larvae was determined after $24 \mathrm{~h}$ and $48 \mathrm{~h}$, respectively. For each setup, at least 50 larvae were examined. *: statistically significant difference ( $p \leq 0.05)$; n.s.: not significant; $\uparrow$ : no data since most of the larvae died.

freezing has no effect on skin permeability. In contrast to that Ahlstrom et al. [24] observed differences in permeability for hydrocortisone between fresh and thawed canine skin, with a higher permeability in thawed skin. Nevertheless these authors also recommend the use of thawed skin, since even if it is a little more permissive than fresh skin, it still serves as limiting factor for diffusion and penetration of pharmaceutics. Although freezing might influence the chemical and physical status of the skin as a barrier, it could be assumed that the migration of hookworm larvae might not be affected to the same extent as the permeability for chemicals. The migration ratios in the present study were nearly identical for the use of fresh and thawed skin, and consequently no statistically significant difference was detected. These results are consistent with results presented by Matthews [25], who also observed no difference in the migratory behaviour of infective larvae of $A$. tubaeforme when using fresh or thawed skin. However, in contrast to migration ratios the skin lag in the present experiments was significantly lower when thawed 
skin was used. This indicates that some larvae remain in the fresh skin, e.g. after being trapped by still active immune cells, or hindered by structures, which might be destroyed by freezing and thawing. Thus, thawed skin might be a more artificial system than fresh skin. However, using the migration ratio as calculation basis for PERL chamber migration experiments, results are comparable. Because of practicability, flexibility as well as animal welfare aspects, thawed skin was used as standard parameter for all further experiments.

Another suggested important parameter concerning larval movement or skin penetration was the incubation temperature. The temperature-depending activity of hookworm larvae and other larvae is a commonly known phenomenon $[9,26,27]$. In the present study larvae also migrated in higher numbers through canine skin, when the temperature was closer to the temperature of the mammalian host. The highest skin lag in the present experiments was observed at $22^{\circ} \mathrm{C}$. This observation is most likely due to the fact, that larvae had obviously started migration but apparently were not able to completely pass through the skin, at least not in the given time of $12 \mathrm{~h}$. Most of the larvae incubated at $7^{\circ} \mathrm{C}$ had not started migration at all after $12 \mathrm{~h}$, so the majority of them could be recovered from the donor compartment, which resulted in a lower skin lag than in the experiment at $22^{\circ} \mathrm{C}$. For the experiments at $32^{\circ} \mathrm{C}$ and $37^{\circ} \mathrm{C}$, most of the larvae were recovered from the acceptor chamber, explaining the low skin lags in these experiments. Although there was no statistically significant difference between the migration and skin lag at $32^{\circ} \mathrm{C}$ and $37^{\circ} \mathrm{C}$, an incubation temperature of $37^{\circ} \mathrm{C}$ was chosen as a standard parameter since this temperature is comparable with the natural host's temperature.

Furthermore, standard PERL chamber experiments were conducted without additional $\mathrm{CO}_{2}$ because the presence of $5 \% \mathrm{CO}_{2}$ led to a decreased migration ratio. Maybe this is due to the fact that under natural conditions the environment at the start of migration is ambient air containing $0.039 \% \mathrm{CO}_{2}$ only. Interestingly, a high percentage of percutaneously migrated larvae used in subsequent feeding assays died within $48 \mathrm{~h}$ in the presence of additional $\mathrm{CO}_{2}$ whereas the other larval populations remained unaffected.

Concerning incubation time, the larvae obviously invaded the skin very quickly, but it took several hours before the majority of larvae were detected within the acceptor chamber. After $12 \mathrm{~h}$ incubation, migration ratios reached a maximum. Longer incubation periods did not result in higher migration or lower skin lag. From in vivo trials with beagles it is known that larvae of $A$. caninum need more time for skin penetration and migration than larvae of $A$. braziliense [28]. Williamson et al. [13] described that in their in vitro assays up to
$100 \%$ of the $A$. caninum larvae had penetrated canine skin within $30 \mathrm{~min}$ and therefore could not be recovered from the skin surface. Such high a penetration was not achieved in the present experiments, and also not after pre-incubation at $37^{\circ} \mathrm{C}$ as performed by Williamson et al [13], which led to even higher numbers of remaining larvae (data not shown).. Thus, the larvae might have been activated before they were actually placed onto the skin. Kopp et al. [22] reported that in their experiments even $84.1 \%$ of the larvae successfully traversed canine skin within $2 \mathrm{~h}$ in contrast to up to 12 hours in the present setup. This rapid penetration and migration can be explained by the use of abdominal skin of very young puppies, generally about 6 weeks of age, and thoroughly removed subcutaneous tissue (S. Kopp, personal communication). Therefore, the barrier the larvae had to penetrate was very thin, whereas in the present study the skin was from dogs, which were at least several months old, and only loose subcutaneous tissue was removed. Another possible explanation could be the used $A$. caninum isolates, but three different isolates tested in the present study behaved comparably (data not shown). However, the present study revealed with approximately $86 \%$ penetrated $A$. caninum larvae within $1 \mathrm{~h}$ a quick invasion into the skin.

The orientation of the skin also influences larval migration and statistically significant differences were observed by testing this parameter. With the epidermal side upwards, $90.3 \%$ of the recovered larvae had completely migrated through the skin, in contrast to $81.0 \%$ when the dermal side was presented. The higher migration ratio with the epidermal side on top is not surprising since it mimics the natural conditions and larvae are attracted by the hair follicle system during migration [28]. The result that the tested acceptor media do not influence migration was expected since larvae most probably do not recognize which medium is beneath the skin, which functions as diffusion and penetration barrier [15].

Exsheathment and initiation of feeding of the thirdstage larvae are assumed to be first steps in the development to parasitic stages $[16,29,30]$. The serum-stimulation method is commonly accepted as a model for the start of parasitic development [31]. However, Hawdon et al. [30] showed that feeding is not necessarily needed for development of hookworms, especially not after oral infection. Unfortunately, there are currently no data available on the percentage of feeding of A. caninum larvae and the time-course of the putative resumption of feeding after percutaneous infection in vivo. Regarding the purpose of feeding, Hawdon et al. [30] hypothesise that feeding is necessary after skin invasion, since the larvae have to cross different tissues (skin, lung etc.) on their way to the small intestine and therefore need 
much more time and energy than after being orally ingested. Therefore, the serum-stimulation resulting in the resumption of feeding presumably mimics percutaneous rather than oral infection in vivo, but lacks the migration step. In the study presented here the pmL3 $-\mathrm{CO}_{2}$ reached maximum feeding levels later than the ssL3 $+\mathrm{CO}_{2}$. This unequal time course may be caused by different stimuli or a different sequence of stimuli. But both, percutaneous migration and serum-stimulation induce exsheathment and feeding, two characteristics currently viewed as first steps of development into parasitic stages. However, since $A$. caninum larvae will usually not come directly into contact with dog serum in vivo before penetrating the skin, it might be assumed that the serum-stimulation omits important stimuli triggering further development. Thus, serum-stimulation alone may not reflect the whole truth. Compared to natural conditions, the PERL chamber percutaneous migration might be more adequate for the examination of molecular mechanisms and changes during the stage conversion towards parasitism. And indeed, larvae migrated through PERL chambers seem to be different from the infective and serum-stimulated larvae. So in current studies on gene transcription patterns in infective, percutaneously migrated, and serum-stimulated hookworm larvae, the obtained preliminary data show good evidence of different transcriptional regulations between these populations.

\section{Conclusions}

The PERL chamber system was optimised and standardised for the percutaneous migration of $A$. caninum larvae. Currently, the model used for activation of $A$. caninum larvae from the free-living to the early parasitic stage is the serum-stimulation method. Interestingly, in this study differences were observed in the time course of resumption of feeding between serum-stimulated and percutaneously migrated larvae. This might indicate that the mechanisms of activation could be different between the two activation methods. In conclusion, the PERL chamber system is considered to be a suitable model to study percutaneous infection and to produce percutaneously migrated larvae for further molecular studies to extend our knowledge of the emergence of the parasitic way of live.

\footnotetext{
Author details

${ }^{1}$ Institute for Parasitology, University of Veterinary Medicine Hannover, Buenteweg 17, 30559 Hannover, Germany. ${ }^{2}$ Novartis Centre de Recherche Santé Animale, St. Aubin, Switzerland.
}

\section{Authors' contributions}

DF and CW carried out the laboratory experiments and statistical analysis, and drafted the manuscript. CW participated in conceiving and designing the migration and feeding assays. CE, CS, and TS conceived and designed the study. All authors participated in data analysis and read and approved the final manuscript.

\section{Competing interests}

The authors declare that they have no competing interests.

Received: 9 December 2010 Accepted: 25 January 2011

Published: 25 January 2011

\section{References}

1. Bethony J, Brooker S, Albonico M, Geiger SM, Loukas A, Diemert D, Hotez PJ: Soil-transmitted helminth infections: ascariasis, trichuriasis, and hookworm. Lancet 2006, 367:1521-1532.

2. Dove WE: Further studies on Ancylostoma braziliense and the etiology of creeping eruption. American Journal of Hygiene 1932, 15:664-711.

3. Traub RJ, Inpankaew T, Sutthikornchai C, Sukthana Y, Thompson RC: PCRbased coprodiagnostic tools reveal dogs as reservoirs of zoonotic ancylostomiasis caused by Ancylostoma ceylanicum in temple communities in Bangkok. Vet Parasitol 2008, 155:67-73.

4. Yacob HT, Ayele T, Fikru R, Basu AK: Gastrointestinal nematodes in dogs from Debre Zeit, Ethiopia. Vet Parasitol 2007, 148:144-148.

5. Saeed I, Maddox-Hyttel C, Monrad J, Kapel CM: Helminths of red foxes (Vulpes vulpes) in Denmark. Vet Parasitol 2006, 139:168-179.

6. Dubna S, Langrova I, Napravnik J, Jankovska I, Vadlejch J, Pekar S, Fechtner J: The prevalence of intestinal parasites in dogs from Prague, rural areas, and shelters of the Czech Republic. Vet Parasitol 2007, 145:120-128.

7. Mittra S, Sasmal NK, Sinha PK: Infectivity of Ancylostoma caninum in dogs by different routes of inoculation. Vet Parasitol 1984, 16:289-293.

8. Haas W, Haberl B, Syafruddin, Idris I, Kersten S: Infective larvae of the human hookworms Necator americanus and Ancylostoma duodenale differ in their orientation behaviour when crawling on surfaces. Parasitol Res 2005, 95:25-29.

9. Granzer M, Haas W: Host-finding and host recognition of infective Ancylostoma caninum larvae. Int J Parasitol 1991, 21:429-440.

10. Sciacca J, Forbes WM, Ashton FT, Lombardini E, Gamble HR, Schad GA: Response to carbon dioxide by the infective larvae of three species of parasitic nematodes. Parasitol Int 2002, 51:53-62.

11. Zietse MA, Klaver-Wesseling JC, Vetter JC: The behaviour of infective Ancylostoma caninum larvae in serum gradients. J Helminthol 1981, 55:203-207.

12. Hotez P, Haggerty J, Hawdon J, Milstone L, Gamble HR, Schad G, Richards F: Metalloproteases of infective Ancylostoma hookworm larvae and their possible functions in tissue invasion and ecdysis. Infect Immun 1990, 58:3883-3892.

13. Williamson AL, Lustigman S, Oksov Y, Deumic V, Plieskatt J, Mendez S, Zhan B, Bottazzi ME, Hotez PJ, Loukas A: Ancylostoma caninum MTP-1, an astacin-like metalloprotease secreted by infective hookworm larvae, is involved in tissue migration. Infect Immun 2006, 74:961-967.

14. Hawdon JM, Jones BF, Perregaux MA, Hotez PJ: Ancylostoma caninum: metalloprotease release coincides with activation of infective larvae in vitro. Exp Parasitol 1995, 80:205-211.

15. Franz TJ: Percutaneous absorption. On the relevance of in vitro data. $J$ Invest Dermatol 1975, 64:190-195.

16. Hawdon JM, Schad GA: Serum-stimulated feeding in vitro by third-stage infective larvae of the canine hookworm Ancylostoma caninum. J Parasitol 1990, 76:394-398.

17. Clokey GV, Jacobson LA: The autofluorescent "lipofuscin granules" in the intestinal cells of Caenorhabditis elegans are secondary lysosomes. Mech Ageing Dev 1986, 35:79-94.

18. Goodey T: A Simple Method of Experimentation for Skin Infection with Hook-worm larvae. Proc $R$ Soc Med 1922, 15:19-20, (Sect Trop Dis Parasitol):

19. Bethony J, Loukas A, Smout M, Brooker S, Mendez S, Plieskatt J, Goud G, Bottazzi ME, Zhan B, Wang Y, Williamson A, Lustigman S, Correa-Oliveira R, Xiao S, Hotez PJ: Antibodies against a secreted protein from hookworm larvae reduce the intensity of hookworm infection in humans and vaccinated laboratory animals. FASEB J 2005, 19:1743-1745.

20. Brown A, Girod N, Billett EE, Pritchard DI: Necator americanus (human hookworm) aspartyl proteinases and digestion of skin macromolecules during skin penetration. Am J Trop Med Hyg 1999, 60:840-847. 
21. Williamson AL, Brindley PJ, Loukas A: Hookworm cathepsin D aspartic proteases: contributing roles in the host-specific degradation of serum proteins and skin macromolecules. Parasitology 2003, 126:179-185.

22. Kopp SR, Kotze AC, MCCarthy JS, Morton JM, Coleman GT: Strategies for the storage of Ancylostoma caninum third-stage larvae. J Parasitol 2008, 94:755-756.

23. Harrison SM, Barry BW, Dugard PH: Effects of freezing on human skin permeability. J Pharm Pharmacol 1984, 36:261-262.

24. Ahlstrom LA, Cross SE, Mills PC: The effects of freezing skin on transdermal drug penetration kinetics. J Vet Pharmacol Ther 2007, 30:456-463.

25. Matthews $B E:$ An in vitro system for investigating the skin-penetrating mechanisms of larval helminths. Trans R Soc Trop Med Hyg 1972, 66:14

26. Khalil M: Thermotropism in Ankylostome Larvae. Proc $R$ Soc Med 1922, 15:16-18, (Sect Trop Dis Parasitol):

27. Bhopale VM, Kupprion EK, Ashton FT, Boston R, Schad GA: Ancylostoma caninum: the finger cell neurons mediate thermotactic behavior by infective larvae of the dog hookworm. Exp Parasitol 2001, 97:70-76.

28. Vetter JC, Leegwater-vd Linden ME: Skin penetration of infective hookworm larvae. III. Comparative studies on the path of migration of the hookworms Ancylostoma braziliense, Ancylostoma ceylanicum, and Ancylostoma caninum. Z Parasitenkd 1977, 53:155-158.

29. Hawdon JM, Volk SW, Pritchard DI, Schad GA: Resumption of feeding in vitro by hookworm third-stage larvae: a comparative study. J Parasitol 1992, 78:1036-1040

30. Hawdon JM, Volk SW, Rose R, Pritchard DI, Behnke JM, Schad GA: Observations on the feeding behaviour of parasitic third-stage hookworm larvae. Parasitology 1993, 106(Pt 2):163-169.

31. Datu BJ, Gasser RB, Nagaraj SH, Ong EK, O'Donoghue P, Mclnnes R, Ranganathan S, Loukas A: Transcriptional Changes in the Hookworm, Ancylostoma caninum, during the Transition from a Free-Living to a Parasitic Larva. PLoS Negl Trop Dis 2008, 2:e130.

doi:10.1186/1756-3305-4-7

Cite this article as: Franke et al: Larval migration in PERL chambers as an in vitro model for percutaneous infection stimulates feeding in the canine hookworm Ancylostoma caninum. Parasites \& Vectors 2011 4:7.

\section{Submit your next manuscript to BioMed Central and take full advantage of:}

- Convenient online submission

- Thorough peer review

- No space constraints or color figure charges

- Immediate publication on acceptance

- Inclusion in PubMed, CAS, Scopus and Google Scholar

- Research which is freely available for redistribution

Submit your manuscript at www.biomedcentral.com/submit
CioMed Central 